\section{SOIL IMPROVEMENT FOR FORESTRY}

HE Reports of the Forest Research Institute of
Sweden, Vol. 36 (Centraltryckeriet, Esselte AB,
Stockholm, 1948) contains papers of considerable
interest. Omitting those dealing with volume and
other measurements made in different parts of the
country, sample plots and yield tables, and papers
on forest pests, an article of importance to other
countries is that of Carl Olof Tamm entitled "Soil-
improving Measures Tried on a Poor Site". The
work is described as a final report on work started
in 1922 by the Swedish Institute of Forest Research
in co-operation with the Forest Protection Board of
the district of Jönköping, following an initiative
taken by W. Lothigius, who was at that time the
Board's executive forest officer. The aim of the work
has been to try some possibilities of raising the poor
forest yield frequently found on sandy soils within the
district and elsewhere in the province of Smaland.
Earlier reports have been published by O. Tamm,
who planned the experiments and was responsible for
collecting data on the plots as long as he remained
with the Institute (up to 1938).

The plots are at lat. $57^{\circ} 34^{\prime} \mathrm{N}$., long. $22^{\circ} 12^{\prime} \mathrm{E}$. They occupy an area known as the Mölna Field on a sand flat that was formerly mostly covered by old forest. In the experimental field, the forest was felled during 1918-19.

After describing the area and its previous vegetative covering, the methods of re-afforestation are treated by means of a number of experimental plots. Nine strips were laid out, numbered III-XI, each $50 \mathrm{~mm}$. wide. Furthermore, the main experiment is divided in ten rows, crossing the strips at right angles. Row No. 7 is $37.5 \mathrm{~m}$. wide, Row No. 8 is $62.5 \mathrm{~m}$.; all other rows are $25 \mathrm{~m}$. wide.

Strips Nos. III and V were sown in 1923 with pine mixed with spruce. In strip No. III the mor cover around each seedspot was loosened and mixed with the sand: no positive effect of this treatment was ever observed. At the same time, strip No. IV was planted with birch (about 1,000 per hectare, side-hole planting) and then sown with pine mixed with spruce. Strip No. VI was planted with Alnus incana instead of birch, and sown with pine.

Strip No. VII and the following strips were planted in 1922, the former with pine $1 / 0$ and spruce $2 / 0$ (ratio $2: 1$ ), No. VIII with birch as No. IV and pine and spruce, No. IX with pine and spruce, No. X with Alnus incana as No. VI and pine, and No. XI with pine only. The conifer seedlings were planted by the slit method.

The number of seedspots per hectare was intended to be 6,000 all over the field, but this figure is rather approximate. All pine and spruce seed used came from the same province; but the birch and Alnus incana seedlings originated from Bastad (Skane).

In Strip No. VII each planting hole was manured with peat from a birch carr ; seven or eight litres of peat were mixed with the earth in each hole before planting. The other treatments were done in different rows. The rows Nos. $1,3,5$ and 7 were controls (no treatment). Within rows Nos. 2 and 6 the soil was ripped by a kind of harrow. Within row No. 4 about $\mathbf{4 0 0} \mathrm{gm}$. lime (calcium carbonate was used from the sulphate mill at Gotafors) was mixed in each hole. Within rows Nos. 8 and 10 tree-debris from the clear felling were removed and taken to row No. 9.
Most of the pines, planted or sown, grew well in the first few following years. The planted spruces grew well, too; but the spruce seed used had a poor capacity of germination. The birches and alder seedlings generally did not stand the hard conditions at Molna Field, especially the frosty climate. Within small areas seedlings of all kinds suffered, either from fungus injuries or from starvation. Attempts were made to fill blanks by repair plantings in 1926 and 1930 .

Two diagrams give results from observations in 1932. The brush-manured row (No. 9) had a small number of seedlings but a high percentage of good pine. Many seedlings were spoiled by capercailzies that found shelter in the brush cover. The peat strip (No. VII) showed a slight excess over the others, both in number of seedlings and in percentage of good pine. None of these deviations is significant.

The paper should be consulted for fyll details. In summing up, the author writes: "The Mölna experiment has been helpful in drawing attention to some factors determining forest yield on poor sandy soils. Yet, in order to have a more definite idea of the parts played by humus conditions, on one hand, and by geology on the other, fresh data must be obtained on plots where the conditions at the start of the experiments are carefully determined. The problems at issue have proved much more complicated than was realized in 1920."

\section{SOME FUNGI OF INDIA}

CIX new species of fungi occurring in Mysore have $\checkmark$ been described by M. J. Thirmulachar (Trans. Brit. Mycol. Soc., 31, 1 ; July 1947). Sphaceloma santali attacks the leaves of the sandal tree; $S$. osyridis parasitizes leaves of Osyris Wightiana; $S$. oleanderi produces an anthracnose on oleander, and $S$. curcumae causes leaf-spot of wild turmerics. Cladochytrium aneurce is an interesting species weakly parasitic within the thallus of a liverwort (Aneura sp.), and Leptosphceria porelloe causes wilting of the bryophyte Porella. Mycological descriptions of the new species are given. Two further new species of Physalospora attacking Pterolobium indicum and Heterostemma tanjorense, two species of Septoria parasitizing Erythrina sp. and Thespesia populnea, with Cereospora adince on its name host, are fully described by T. S. and K. Ramakrishnan (Proc. Ind. Acad. Sci., B, 26, No. 1, 7 ; July 1947).

Several papers have also been published on Phytophthora palmivora, which causes a fruit rot of tomatoes and a seedling blight of Hibiscus esculentus. T. S. Ramakrishnan and C. K. Soumini have studied the fungus on tomatoes (Proc. Ind. Acad. Sci., B, 25, No. 2, 39; Feb. 1947). They isolated the fungus, proved its pathogenicity, found it could enter unwounded fruits, and, as infection appears most readily on fruits in contact with the soil, suggested proper support of tomato plants as a simple means of prevention. M. S. Balakrishnan (Proc. Ind. Acad. Sci., B, 26, No. 4, 142 ; Oct. 1947) established the pathogenicity of $P$. palmivora on Hibiscus seedlings. A minus strain was isolated, and did not form oospores until paired with a plus strain of the same species. Further studies on this heterothallism have been made by K. M. Thomas, T. S. Ramakrishnan, C. K. Soumini and M. S. Balakrishnan (Proc. Ind. Acad. Sci., B, 26, 147 ; Oct. 1947).

R. P. Asthana has investigated several characters of Sclerotium cepivorum and S. tuliparum (Proc. Ind. 